OPEN ACCESS

Edited by:

Jing-wen Lin,

Sichuan University, China

Reviewed by:

Viswanathan Natarajan,

University of Illinois at Chicago,

United States

Tracey Lamb,

The University of Utah, United States

*Correspondence:

Gunanidhi Dhangadamajhi gunarmrc@gmail.com

Specialty section:

This article was submitted to

Parasite and Host

a section of the journal

Frontiers in Cellular and Infection

Microbiology

Received: 18 March 2020

Accepted: 08 June 2020

Published: 14 August 2020

Citation:

Dhangadamajhi G and Singh S (2020)

Sphingosine 1-Phosphate in Malaria

Pathogenesis and Its Implication in

Therapeutic Opportunities.

Front. Cell. Infect. Microbiol. 10:353.

doi: $10.3389 /$ fcimb.2020.00353

\section{Sphingosine 1-Phosphate in Malaria Pathogenesis and Its Implication in Therapeutic Opportunities}

\author{
Gunanidhi Dhangadamajhi ${ }^{1 *}$ and Shailja Singh ${ }^{2}$ \\ ${ }^{1}$ Department of Biotechnology, North Orissa University, Baripada, India, ${ }^{2}$ Special Centre for Molecular Medicine, Jawaharlal \\ Nehru University, New Delhi, India
}

Sphingosine 1-Phosphate (S1P) is a bioactive lipid intermediate in the sphingolipid metabolism, which exist in two pools, intracellular and extracellular, and each pool has a different function. The circulating extracellular pool, specifically the plasma S1P is shown to be important in regulating various physiological processes related to malaria pathogenesis in recent years. Although blood cells (red blood cells and platelets), vascular endothelial cells and hepatocytes are considered as the important sources of plasma S1P, their extent of contribution is still debated. The red blood cells (RBCs) and platelets serve as a major repository of intracellular S1P due to lack, or low activity of S1P degrading enzymes, however, contribution of platelets toward maintaining plasma S1P is shown negligible under normal condition. Substantial evidences suggest platelets loss during falciparum infection as a contributing factor for severe malaria. However, platelets function as a source for plasma S1P in malaria needs to be examined experimentally. RBC being the preferential site for parasite seclusion, and having the ability of trans-cellular S1P transportation to EC upon tight cell-cell contact, might play critical role in differential S1P distribution and parasite growth. In the present review, we have summarized the significance of both the S1P pools in the context of malaria, and how the RBC content of S1P can be channelized in better ways for its possible implication in therapeutic opportunities to control malaria.

Keywords: sphingosine 1-phosphate, malaria, RBC, rosette, therapeutic

\section{INTRODUCTION}

Chemotherapeutics is the mainstay of malaria control in absence of high efficacy approved vaccine and ineffective vector control measures (Tibon et al., 2020). Unfortunately, parasite resistance to almost all the current pharmacotherapy is a major threat to control malaria. Despite high incidence, luckily, only a minority of individuals (1-2\%) develop the malaria attributed complicacy. However, notable numbers (15-20\%) of these patients still succumb to death even after effective antimalarial treatment (Dondorp et al., 2010; Newton et al., 2013) and thus requires the most urgent attention and intensive care. The complex interactions between the malaria parasite and human host leading to adhesion phenotypes (such as cyto-adherence, rosetting, and platelet mediated clumping), endothelial dysfunction, deregulation of the homeostasis system, host inflammatory response and nitric oxide (NO) production are thought to be the key events (van der Heyde et al., 2006; Yeo et al., 2008; Rowe et al., 2009). In other words, host response to malaria infection is of paramount importance in determining inter-individual variation in disease severity in malaria. Host response 
in malaria research has primarily focused on protein component and lipids were usually appraised for their role in cell membrane formation or energy storage. Recently, Sphingosine 1-Phosphate (S1P), a pleiotropic lysophospholipid has been shown to affect various cellular pathways including the immune and vascular systems which are implicated in the pathology of severe malaria (Snider et al., 2010; Lou et al., 2011; Xiong et al., 2014). S1P is present in almost all cells and body fluids. However, it is one of the important components of blood, distributed differentially in blood cells and plasma, thereby regulating various physiological processes. In the present review, attempt has been made to highlight the current knowledge on S1P metabolism, cellular sources of plasma S1P, their transport and biological function based on the available literatures. In addition to this, we compiled the importance of S1P in the context of clinical malaria. Besides, RBC being the major source of S1P and preferential site for parasite seclusion, how RBC content of S1P could be channelized in a beneficial way for possible malaria control have been discussed.

\section{S1P METABOLISM AND PLASMA SOURCE OF S1P}

Shingosine, named after Sphinx, a Greek mythical creature of enigmatic activity is one of the important intermediate in sphingolipid metabolism. S1P is produced mostly through intracellular phosphorylation of sphingosine, a deacylated product of ceramide in various cell types by two isoform of sphingosine kinases (SPHK1 and SPHK2) (Ksiazek et al., 2015; Hatoum et al., 2017). Ceramide in turn is generated either from the condensation of serine and palmitoyl-CoA in a de novo pathway by serine palmitoyltransferase in the endoplasmic reticulum (ER), or from degradation of membrane sphingolipids (such as sphingomyelin and glycosphingolipids) in lysosomes or in the outer leaf-let of cellular membranes (Maceyka and Spiegel, 2014; Thuy et al., 2014; Ksiazek et al., 2015; Cantalupo and Di Lorenzo, 2016). The SPHK1 and SPHK2 kinases which phosphorylate sphingosine into S1P have different sub-cellular localization and tissue distribution (Maceyka et al., 2005). While SPHK1 is localized in cytosol (Pitson et al., 2005; Chan and Pitson, 2013) and highly substrate specific (Ksiazek et al., 2015), SPHK2 is mainly found in the nucleus, mitochondria, and ER (Cantalupo and Di Lorenzo, 2016) with broader range substrate specificity (Venkataraman et al., 2006; Maceyka and Spiegel, 2014). Further, of the two isoforms, only SPHK1 is shown to be released out of the endothelial cells constitutively, and the rate of extracellular S1P synthesis by SPHK1 is dependent on the level of spingosine present in the extracellular medium (Ancellin et al., 2002; Venkataraman et al., 2006; Takabe et al., 2008). However, its contribution as an additional source of plasma S1P in human is not clearly known. Moreover, it remains to be seen whether malaria infection has any impact on endothelial cell release of SPHK1 in extracellular milieu. It is established that S1P level in plasma and lymph is maintained relatively high compared to its concentration in tissues (Schwab et al., 2005; Peest et al., 2008; Takabe et al., 2008). Further, this differential gradient of S1P has been shown important in regulating various physiological function (Kerage et al., 2014; Cantalupo and Di Lorenzo, 2016; Cartier and Hla, 2019).

It is to be noted that blood harbors S1P in blood cells as well as in plasma (Figure 1). However, plasma S1P has a short half-life period (Venkataraman et al., 2008; Salous et al., 2013) which indicates its rapid clearance and instant replenishment in a well-regulated process. Although blood cells such as RBC and platelets, vascular endothelial cell, and hepatocytes are considered as the important sources of plasma S1P, their extent of contribution is still debated (Tani et al., 2007; Venkataraman et al., 2008). The balance between synthesis and export of S1P, and its intracellular or extracellular degradation by three types of enzymes is crucial in maintaining plasma level S1P. The intracellular degradation of S1P is carried out by two endoplasmic reticulum localized enzymes, such as (i) S1P phosphatases (SPP), which reversibly dephosphorylate S1P into sphingosine and (ii) S1P lyases (S1PL), which irreversibly inactivate S1P in to hexadecenal and ethanolamaine-1-phosphate (Bandhuvula and Saba, 2007; Liu et al., 2012). The degradation of S1P in extracellular space is carried out by the ecto-enzyme lipid phosphate phosphatases (LPP1 and LPP3) found in the plasma membrane of endothelial cell, and platelets (Yatomi et al., 2004; Zhao et al., 2007; Salous et al., 2013), which dephosphorylates most of the lipid phosphates including S1P. The S1P in the cell can also be dephosphorylated by another isoforms of LPP, the LPP2 which resides intra-cellularly (Kai et al., 2006). Of note, circulating S1P is rapidly dephosphorylated by LPPs into sphingosine (Zhao et al., 2007), where the latter is taken up by the blood cells and platelets (Tani et al., 2005; Ksiazek et al., 2015) for intracellular synthesis of S1P (Zhao et al., 2007). Besides, sphingosine can also be generated from membrane sphingolipids in these cells.

Of the various cell types, RBC synthesize S1P mainly via SPHK1, whereas platelets synthesize via SPHK2 and they both accumulate large amount of S1P due to lack of cellular organelles and S1P degrading enzymes (Hanel et al., 2007; Zhao et al., 2007; Bode et al., 2010; Urtz et al., 2015). Although the platelet content of S1P is relatively higher than that is in the RBC (Anada et al., 2007; Ito et al., 2007), the majority of S1P in the plasma pool of healthy individuals is contributed by RBC, possibly due to its largest share in total blood cell numbers (Hanel et al., 2007; Ito et al., 2007) and that the platelets release S1P only upon activation (Ohkawa et al., 2008; Ono et al., 2013). It is shown that human platelets can also constitutively release S1P without stimulation depending upon the presence of high albumin concentration in the plasma (Jonnalagadda et al., 2014). However, the observation of normal level of plasma S1P in thrombocytopenic or plateletdeficient mice (Pappu et al., 2007; Venkataraman et al., 2008) and non-correlation of platelet count with S1P level in human study (Ohkawa et al., 2008) suggest the contribution of platelet toward maintaining plasma S1P is negligible under normal condition. Interestingly, while genetic and pharmacological inhibition of Sphk 1 has shown reduction in plasma level of S1P by $50 \%$ (Kharel et al., 2011), similar studies with Sphk2 (which encodes the major enzyme for platelet S1P synthesis) showed opposite results (Sensken et al., 2010; Kharel et al., 2012). This also supports the 


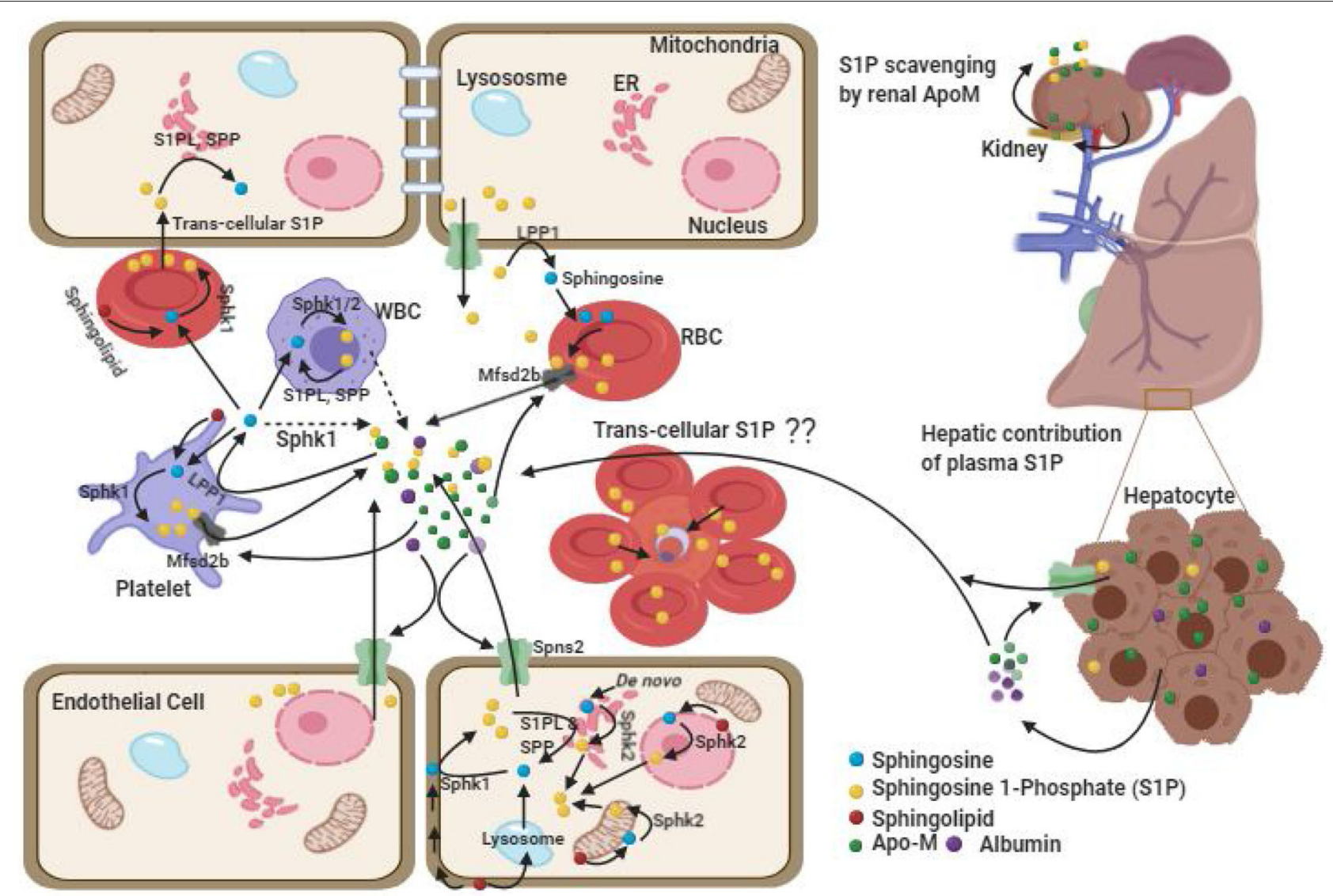

FIGURE 1 | Plasma Sources of cellular S1P. There are two pools of S1P, intracellular and extracellular each with different functions. The intracellular pool is synthesized upon incorporation of the substrate from plasma or its generation within the cell followed by phosphorylation by resident kinases such as SPHK1 in cytosol and SPHK2 in mitochondria, ER and nucleus. The intracellular S1P can be degraded by S1PL and SPP enzymes. The extra-cellular pool of S1P is predominantly maintained by cellular efflux of S1P facilitated by the acceptor molecules (ApoM-HDL and albumin) and possibly by endothelial cell secretion of SPHK1 which converts sphingosine in extracellular space into S1P (dashed arrow). RBCs play important role by functioning as a major reservoir for intracellular and extra-cellular S1P. In absence of acceptor molecule, RBC transports the S1P to EC and other cells through trans-cellular transportation after tight cell-cell contact. While, ECs have been demonstrated as alternative source for plasma S1P, platelets contributes to the extracellular pool only upon activation. Hepatocytes by secreting ApoM stimulate S1P export from hepatic and extra-hepatic cells, whereas kidney derived ApoM function to prevent urinal secretion of S1P and is metabolized in the kidney itself. The (??) in the figure depicts possible trans-cellular transportation of S1P from un-infected RBC to infected RBC in rosette.

non-significant role of platelets toward plasma S1P. In humans, although the cellular content of S1P in RBC of both anemic and healthy individuals is found to be comparable (Bode et al., 2010; Selim et al., 2011), significantly reduced plasma S1P level in anemic patients suggests the major role of RBC in contributing S1P in human blood (Hanel et al., 2007; Bode et al., 2010; Selim et al., 2011). This was further strengthened by the observation that in Sphk1/Sphk2 deficient mice, transfusion of only wild type erythrocytes but not the platelets and leukocytes restored normal S1P level in plasma (Pappu et al., 2007). Further, significant correlation of RBC parameters with plasma S1P and the findings of higher plasma S1P in men, compared to women (Ohkawa et al., 2008) highlight RBC as the important source of blood $\mathrm{S} 1 \mathrm{P}$. Although gender difference in plasma S1P level was shown controversial in other studies (Hammad et al., 2010; Karuna et al., 2011), it is attributed to be due to remarkable decrease in plasma
S1P post-menopause in women because of estrogen deficiency (Guo et al., 2014) and the inclusion of older age group in the study (Guo et al., 2014).

Spontaneous S1P efflux from vascular endothelial cells have also been documented similar to RBCs and could serve as an alternative source in replenishing plasma S1P at least in mice (Venkataraman et al., 2008; Fukuhara et al., 2012; Hisano et al., 2012). Shear stress and down regulation of intracellular S1P degrading enzymes have been shown to enhance S1P efflux from ECs (Venkataraman et al., 2008). However, it could not be replicated in human studies (Zhao et al., 2007). The contribution of WBCs toward plasma S1P is almost none and suggested to be due to its high rate of degradation than the rate of its release (Hanel et al., 2007; Salous et al., 2013). Consistent to this, no correlation between WBCs count with S1P has been found (Pappu et al., 2007; Ohkawa et al., 2008). The role of hepatocytes 
in S1P homeostasis is related to its over expression of ApoM (Kurano et al., 2013; Nojiri et al., 2014), the major acceptor of circulating S1P which stimulates S1P export from hepatic and extra-hepatic cells (Liu et al., 2014; Huang et al., 2015). Although liver and kidney cells secrete ApoM (Zhang et al., 2003; Huang et al., 2015), plasma level of ApoM which mainly associates with HDL is predominantly secreted by liver cells. Liver derived ApoM play a major role in sphingolipid recycling, and in the maintenance of the plasma level of ApoM/S1P-enriched HDL besides whole body S1P distribution and homeostasis (Venkataraman et al., 2008; Christoffersen et al., 2011; Kurano et al., 2013). However, renal-ApoM by functioning as an S1P scavenger is metabolized in the kidney itself after re-absorption in the renal proximal tubule through the megalin receptor and prevent urinal secretion of S1P (Faber et al., 2006). Altogether, $\mathrm{RBC}$ is the major source of plasma S1P in humans but vascular $\mathrm{EC}$ and RBCs are equally important in maintaining blood S1P in mice.

\section{EXPORT OF INTRACELLULAR S1P, ACCEPTOR MOLECULES AND THEIR EFFECT ON S1P FUNCTION}

Having a polar head group, the export of cellular S1P to plasma is carried out through transporters like spinster homolog 2 (Spns2) from endothelial cells in a non-ATP dependent manner (Fukuhara et al., 2012; Hisano et al., 2012; Mendoza et al., 2012; Donoviel et al., 2015) or through major facilitator superfamily transporter $2 \mathrm{~b}$ (Mfsd2b) from RBCs and platelets in an ATP dependent manner (Vu et al., 2017; Kobayashi et al., 2018). Moreover, being poorly water soluble, the release of S1P to plasma is facilitated by the presence of extracellular acceptor molecules such as HDL (most notably ApoM-HDL which carries $70 \%$ of S1P), or albumin (which carries $30 \%$ of S1P). Intracellular $\mathrm{S} 1 \mathrm{P}$ efflux to plasma has been decreased upon dilution of plasma or prevented in serum/plasma free medium (Hanel et al., 2007; Venkataraman et al., 2008; Bode et al., 2010; Christoffersen et al., 2011; Karuna et al., 2011; Sutter et al., 2014). Further, in absence of the S1P acceptor molecules (albumin and ApoM) in plasma, RBC may contribute to S1PL degradable cellular pool of S1P through trans-cellular S1P transportation to EC and other tissue cells upon tight cell-cell contact (Bode et al., 2010). This indicates that RBC content of S1P and the acceptor molecules play critical role in differential distribution and degradation of S1P.

Recent studies have shown that the S1P efflux from EC, $\mathrm{RBC}$, and platelets, and their effective circulation in the plasma and specific biological function is dependent on its association with the type of acceptor molecule. Of note, the rate of release of S1P from RBC is enhanced by the ApoM-HDL (Bode et al., 2010; Wilkerson et al., 2012; Yu et al., 2014) and from the platelets by albumin (Jonnalagadda et al., 2014). Further, functional differences in evoking intracellular signaling between ApoM-S1P and albumin-S1P exist (Wilkerson et al., 2012; Galvani et al., 2015; Obinata and Hla, 2019), albeit the reason for this remains poorly understood. It is suggested that while albumin is indiscriminating in binding to various small hydrophobic molecules including S1P (Obinata and Hla, 2019), ApoM has high affinity for S1P and is a specific chaperone that protects the bound S1P from degradation by LPP (Kimura et al., 2001; Christoffersen et al., 2011; Zhang et al., 2016). Moreover, ApoM-bound S1P in a context-dependent signaling has been shown to mediate prolonged receptor activation for several hours compared to transient activation by albumin in evoking downstream cascade (Wilkerson et al., 2012; Swendeman et al., 2017). While albumin-bound S1P has been found to be associated with diminished cAMP production and efficient S1PR 1 -internalization (Galvani et al., 2015; Obinata and Hla, 2019), ApoM-S1P has been observed to regulate lymphopoiesis in bone marrow (Blaho et al., 2015) and maintain vascular integrity through anti-inflammatory responses in endothelial cells (Galvani et al., 2015; Sattler et al., 2015; Keul et al., 2019). Interestingly, engineered ApoM with long plasma half-life (about $90 \mathrm{~h}$ ) and the potential to bind S1P (such as ApoM-Fc) was when intraperitoneally administered to the experimental model of stroke in mice, an increase in plasma S1P concentration by $30 \%$ was recorded post $24 \mathrm{~h}$ with protection from myocardial damage after ischemia, together with reduction of hypertension and brain infarct volume compared to the control ApoM of comparable half-life with no S1P binding ability (ApoM-Fc-TM) (Swendeman et al., 2017). Moreover, the association of low level HDL-S1P content with coronary artery disease (Sattler et al., 2010), and type II diabetes (Tong et al., 2014) in case-control human studies evidence for the potential beneficial role of ApoM$\mathrm{S} 1 \mathrm{P}$ in these diseases. However, it remains to be elucidated how plasma S1P level and the S1P bound receptors affect the pathological conditions in human malaria.

Although intracellular receptor for S1P is not wellcharacterized, it is shown to regulate important intracellular function like ubiquitination, histone deacetylation and gene expression, and respiration (Hait et al., 2009; Alvarez et al., 2010; Sun et al., 2016). On the other hand, the extracellular S1P exerts its diverse effects in an autocrine or paracrine manner through five G-protein coupled receptors $\left[\mathrm{S}_{\mathrm{P}} \mathrm{PR}_{1-5}\right.$, initially termed as endothelial differentiation gene (EDG)]. These S1PRs vary in their distribution and expression in response to various stimuli (Strub et al., 2010; Blaho and Hla, 2014). Of the five receptors $\left(\mathrm{S}_{1} \mathrm{PR}_{1-5}\right), \mathrm{S}_{1} \mathrm{PR}_{4-5}$ have much narrower patterns of expression compared to $\mathrm{S}_{1} \mathrm{PR}_{1-3}$ receptors, with ubiquitous expression of $S 1 \mathrm{PR}_{1}$ in the brain, kidney, lung, spleen and cardiovascular system (Strub et al., 2010; Blaho and Hla, 2014). While $S 1 \mathrm{PR}_{1}$ regulates immune cell function including lymphocyte egress from lymph nodes (Liu et al., 2000; Schwab et al., 2005; Sanna et al., 2006), S1PR 2 is required for vestibular and auditory systems development (MacLennan et al., 2006; Ingham et al., 2016; Hofrichter et al., 2018), whereas $\mathrm{S}_{\mathrm{PR}} \mathrm{PR}_{3}$ is required for regulation of heart rate (Forrest et al., 2004). Further, $\mathrm{S}_{\mathrm{PR}} \mathrm{R}_{1-3}$ receptors play an important role in angiogenesis and vascular permeability (Strub et al., 2010). A study involving triple knockout of $\mathrm{S}_{1} \mathrm{PR}_{1-3}$ has led to the embryonic lethality in mice due to the massive vascular deficiencies (Kono et al., 2004). Since, vascular injury is common in severe falciparum malaria; we hypothesize for the possible involvement of $\mathrm{S}_{\mathrm{PR}} \mathrm{PR}_{1-3}$ receptors including plasma level of $\mathrm{S} 1 \mathrm{P}$ in severe malaria. 
Although the S1P concentration in plasma and its subsequent effect on malaria could possibly be due to genetic variation, there is lack of information on mutations in genes affecting S1P synthesis (Sphk1, Sphk2), degradation (Spl, Spp1, Spp2) and signaling receptors $\left(S 1 p r_{1-3}\right)$ leading to plasma level of S1P concentration and clinical outcome in malaria. Screening of functional genetic variations in these genes may be useful for better understanding of S1P biology in malaria.

\section{S1P AND ITS ASSOCIATION WITH MALARIA}

To date, only few studies have exploited the role of S1P in malaria. Recent studies have highlighted the dysregulation of the S1P pathway mostly in the pathogenesis of CM in mice (Table 1). Reduced plasma S1P has been found to be associated with malaria severity and impaired neuro-cognitive functions in mice (Table 1). In Ugandan children with CM, the plasma S1P level was significantly less compared to uncomplicated malaria (Finney et al., 2011) consistent to the results obtained in experimental malaria. Severe neurological sequelae are also common in human CM, often associated with death in children post-discharge from hospital (Idro et al., 2010; Oluwayemi et al., 2013). Of note, increased bio-availability of S1P has been shown to inhibit neurological signs and prolonged survival in experimental CM (Finney et al., 2011; Nacer et al., 2012, 2014) indicating S1P enrichment in plasma could be a rational means of new therapeutics strategy, although it has to be established in human studies. Further, the involvement of $\mathrm{S} 1 \mathrm{P}$ receptors, specifically increased $\mathrm{S} 1 \mathrm{PR}_{3}$ concentration with mortality has been documented in acute lung injury (ALI)/acute respiratory distress syndrome (ARDS) patients (Sun et al., 2012), yet another severe complication of falciparum malaria which ranges from 5 to $25 \%$ of adults and $29 \%$ of pregnant women (Taylor et al., 2012). Anticipating implication of circulating $\mathrm{S}_{\mathrm{PRR}}$ as a potential biomarker of severity in malaria induced ARDS, when the expression of the $S p h k 1$ and $S 1 \mathrm{PR}_{3}$ proteins were investigated in malaria-associated ALI/ARDS, up-regulated expression of these were demonstrated in the lung tissues of experimental mice and human malaria patients (Punsawad and Viriyavejakul, 2019; Viriyavejakul and Punsawad, 2020). However, agreeing to evidence from previous studies (Finney et al., 2011; Punsawad and Viriyavejakul, 2017), plasma and lung tissues level of S1P was significantly less in malaria infected mice with ALI/ARDS) compared to non-ALI/ARDS and control (Punsawad and Viriyavejakul, 2019). Although the reason for $S 1 \mathrm{P}$ reduction remains unknown, it can be surmised that Sphk1 and $S_{1 p r_{3}}$ expression in lung tissues do not contribute much for tissue fluids or plasma level of S1P. A recent knockout study in Pseudomonas aeruginosa induced lung inflammation revealing the pathogenic role of SPHK2 through epigenetic regulation of gene expression and intracellular S1P generation (Ebenezer et al., 2019) proposes the possible collusion of SPHK2 in malaria induced ARDS. Further studies with Sphk1, Sphk2, and $S 1 p r_{3}$ knockout mice or antagonists may help understanding their involvement in ALI/ARDS and unveil the reason for S1P reduction. These findings are of particular interest and indicate the possible protective nature of S1P in severe malaria; however the role of S1P in malaria is still unclear.

Endothelial dysfunction leading to loss of vascular integrity and leakage is the key to the pathogenesis of severe malaria (van der Heyde et al., 2006; Liles and Kain, 2014). Accelerated breakdown of endothelial glycocalyx leading to endothelial cell (EC) activation and exposure of EC surface receptors for parasite sequestration has been documented during severe malaria (Hempel et al., 2019; Yeo et al., 2019). Interestingly, inverse association of S1P with endothelial glycocalyx breakdown products have been demonstrated in Indonesian adults patients with falciparum infection (Yeo et al., 2019). Further, increased permeability of endothelial cells induced by sera from individuals with complicated falciparum malaria has been found to reverse with phosphorylated FTY720, an S1P agonist (Oggungwan et al., 2018). This indicates that S1P bioavailability could be instrumental in attenuating endothelial damage and ensuing protection from severe malaria. Previous study examining the impact of S1P bioavailability through S1P lyase deficiency in ECM has documented improved survival in mice (Finney et al., 2011), which further resolves the importance of S1P in effective therapeutics against malaria. Disruption of vascular integrity in the blood-brain barrier (BBB) is often associated with poor outcome in CM. Moreover, increased vascular integrity and significant survival advantage have been observed in murine model of CM upon prophylactic or early therapeutic treatment with FTY720. However, therapeutic intervention with FTY720 in later stage infection (3-5 days) in the same study was ineffective against ECM (Finney et al., 2011). Notably, administration of FTY720 in combination with sub curative dose of artesunate (the most potent antimalarial drug against all forms of severe malaria) in late stage infection resulted in improved survival from ECM with unaltered parasite burden compared to artesunate alone (Finney et al., 2011) indicating that the protective effect was especially through host response modulation. Artesunate is shown protective against malaria by its direct parasite killing activity and indirect immune-modulatory effect such as prevention of endothelial cell activation, cyto-adherence of parasite infected RBCs, and amelioration of blood-brain barrier (BBB) breakdown (Souza et al., 2012). Recent study documents artesunate mediated alleviation of $\mathrm{BBB}$ disruption to be through activation of $\mathrm{S}_{\mathrm{PR}}$, downstream phosphatidylinositol 3-kinase/AKT signaling, and stabilization of $\beta$-catenin (Zuo et al., 2017). Although FTY720 too activates S1PRs (except $S 1 \mathrm{PR}_{2}$ ) initially, it down regulates $S 1 \mathrm{PR}_{1}$ function through irreversible induction of $\mathrm{S}_{\mathrm{PR}}$ internalization and degradation (Oo et al., 2011). It remains unknown how FTY720 modulates the action of artesunate in improving survival from later stage ECM in combination treatment. Nonetheless, these findings are immensely important to include S1P agonists as potential adjunctive therapeutics for malaria treatment. It is suggested that reduced lymphocyte count in the blood due to impaired lymphocyte egress with significant restriction of immune cells infiltration into the brain upon FTY720 treatment as prophylactic or early therapeutic drug could be the contributing factor for protection against CM (Finney et al., 2011). However, in late stage treatment, when there was already advancement in leukocyte egress and subsequent recruitment to brain had begun 
TABLE 1 | Association of S1P with experimental infection of malaria and clinical malaria in human.

\begin{tabular}{lll}
\hline S. No & Organism or cell & Experimentation \\
\hline 1 & Human & The SPHK-1 activity and its \\
Erythrocytes & $\begin{array}{l}\text { phosphorylation status were compared } \\
\text { between uninfected and } \\
\text { P. falciparum-infected erythrocytes in vitro } \\
\text { in different stages of asexual development. }\end{array}$ \\
& Intracellular parasitic growth was assessed \\
& Human & upon pharmacological inhibition of host \\
& Erythrocytes &
\end{tabular}

3

DBA/2 mice

4

HUVECS

5

CBA/CaJ mice

6

CBA/CaJ mice

C57BL/6

8

Human

9

Human
Plasmodium berghei ANKA infected mice were divided into two groups: with and without ALI/ARDS. Expression of the SphK-1 and S1PR-3 proteins was investigated

Endothelial cells were incubated with malaria infected and non-infected human sera for induction of permeability. Treatment with FTY720 before and after incubation of sera was evaluated for restoration of permeability.

Mice were infected with $P b A$ for induction of ECM and with Plasmodium yoelii for malarial hyperparasitemia without neurological impairment. Treatment with FTY720 was investigated to understand the pathogenesis

Mice infected with $P$. berghei ANKA strains were evaluated for recovery upon FTY720 treatment (oral dose of $0.3 \mathrm{mg} / \mathrm{kg} /$ day, starting 1 day before infection)

Mice infected with PbA (ECM) were treated with FTY720 $1 \mathrm{~d}$ prior to and 1, 3, or $5 \mathrm{~d}$ post-infection to evaluate the possible involvement of S1P in endothelial dysfunction and survival. In order to examine whether increased S1P bioavailability affect survival in ECM, parasite infected mice deficient of S1PL was compared with wild-type littermates

Plasma S1P levels was compared between falciparum infected Ugandan children with CM and UM to examine the significance of S1P in human malaria

S1P levels in serum of adult Indian malaria patients (falciparum and vivax infected) were compared to healthy controls
Findings

A significant decrease in SPHK-1 phosphorylation and activity were observed in a time-dependent manner in falciparum-infected erythrocytes compared to uninfected RBCs.

Intracellular reduction of S1P in erythrocytes impaired glycolysis, low level of lactate was released as bi-product; parasite growth was affected leading to cell death. Impaired glycolysis was attributed to be due to decreased translocation of GAPDH from membrane to site of function in cytosol in infected $\mathrm{RBC}$.

Upregulated expression of the SphK-1 and S1PR-3 proteins was observed in endothelial cells, alveolar epithelial cells and alveolar macrophages in the lung tissues of ALI/ARDS group compared to control group. However, S1P in plasma and lung tissues was significantly less in ALI/ARDS group compared to control mice.

Significantly high permeability was recorded after incubation with serum from complicated patients with falciparum malaria compared to uncomplicated falciparum patients and vivax infected patients. Treatment with FTY720 before and after incubation of sera significantly reduced and prevented sera induced increase in endothelial cell permeability Recruitment of activated leukocytes (CD8 + T cells and ICAM+ macrophages), and neutrophils to post-capillary venules prevents venous blood efflux from the brains severely, which leads to vasogenic edema in ECM. Cells arrest in vasculature is likely to increase the intracranial pressure leading to poor clinical outcome. Treatment with FTY720 prevents these cells recruitment and protect from death in ECM.

$P$. berghei ANKA induced ECM with neurological signs, cerebral hemorrhages, and BBB dysfunction. FTY720 inhibited vascular leakage and neurological signs, stabilized BBB and prolonged survival to ECM.

FTY720 treatment in 1 day-pre-infection and 1 day-post-infection improved BBB integrity in ECM compared to untreated infected mice, and day 3 post-infection treated mice. Lymphocyte counts were markedly reduced in blood and their infiltration (both $\mathrm{CD}^{+}$and $\mathrm{CD}^{+}$cells) in the brain was decreased. Further, treatment with FTY720 suppressed endothelial dysfunction and reduced plasma level of IFN $r$. FTY720 in combination with sub-curative dose of artesunate treatment on $5 d$ post-infection resulted in improved survival compared to artesunate therapy alone. Increased bioavailability of S1P due to S1PL deficiency in knockout mice was associated with improved outcome compared to wild-type littermates

Plasma level of S1P was significantly less in children with cerebral malaria compared to UM. Also hemoglobin and platelet levels were highly reduced in $\mathrm{CM}$

S1P level was significantly less in malaria patients compared to healthy control. Complicated malaria patients had the lowest S1P level, and platelet count positively correlated with S1P level
References

(Sah et al., 2020)

(Sah et al., 2019)

(Punsawad and

Viriyavejakul, 2019)

(Oggungwan et al., 2018)

(Nacer et al., 2014)

(Nacer et al., 2012)

(Finney et al., 2011)

(Finney et al., 2011)

(Sah et al., 2020) 


\begin{tabular}{|c|c|c|c|c|}
\hline S. No & Organism or cell & Experimentation & Findings & References \\
\hline & Human & $\begin{array}{l}\text { Autopsied patients who died with } \\
\text { P. falciparum malaria were categorized into } \\
\text { PE and Non-PE group, and cellular } \\
\text { expression of SPHK-1 and S1PR-3 were } \\
\text { investigated using immune histochemistry. }\end{array}$ & $\begin{array}{l}\text { Over expression of both SPHK-1 and S1PR-3 } \\
\text { proteins were observed in lung tissues of PE } \\
\text { indicating their role in the pathogenesis of } \\
\text { pulmonary complications in severe malaria. }\end{array}$ & $\begin{array}{l}\text { (Viriyavejakul and } \\
\text { Punsawad, 2020) }\end{array}$ \\
\hline 10 & Human & $\begin{array}{l}\text { Endothelial glycocalyx breakdown } \\
\text { products, markers of endothelial } \\
\text { dysfunction, parasite biomass, S1P and } \\
\text { NO levels were compared between } \\
\text { Indonesian adults with falciparum malaria } \\
\text { (severe and moderately severe) and } \\
\text { healthy control }\end{array}$ & $\begin{array}{l}\text { Inverse correlation between S1P and breakdown } \\
\text { products of endothelial glycocalyx was observed. } \\
\text { Glycocalyx breakdown was associated with } \\
\text { endothelial dysfunction, low NO bioavailability, } \\
\text { increased parasite biomass, severity of malaria and } \\
\text { risk of death. }\end{array}$ & (Yeo et al., 2019) \\
\hline 11 & Human & $\begin{array}{l}\text { Serum S1P levels were measured in Thai } \\
\text { patients with } P \text {. vivax, uncomplicated } \\
P \text {. falciparum, and complicated } \\
P \text {. falciparum malaria on day } 0 \text { and on day } \\
\text { 7. These values were compared to that of } \\
\text { healthy control }\end{array}$ & $\begin{array}{l}\text { Low serum S1P was associated with severity of } \\
\text { malaria on day of admission which increased to } \\
\text { significant level on day } 7 \text {. Platelet count, } \\
\text { hemoglobin and hematocrit values were positively } \\
\text { correlated with serum S1P level in severe falciparum } \\
\text { malaria patients }\end{array}$ & $\begin{array}{l}\text { (Punsawad and } \\
\text { Viriyavejakul, 2017) }\end{array}$ \\
\hline
\end{tabular}

GAPDH, Glyceraldehyde 3-phosphate dehydrogenase; SPHK1, Sphingosine kinase 1; ALI/ARDS, acute lung injury/acute respiratory distress syndrome; HUVEC, Human umbilical vein endothelial cell; ECM, Experimental cerebral malaria; BBB, Blood-brain-barrier; UM, Uncomplicated malaria; PE, Pulmonary edema; S1PL, Sphingosine-1-phosphate lyase.

(a process involved in CM pathology), attempt to recover mice could have been difficult (Finney et al., 2011; Nacer et al., 2012, 2014). Artesunate has been proven beneficial against late stage ECM independent of parasite killing and is attributed to be due to the reduction of endothelial dysfunction, and leuckocyte detachment from brain vasculature (Clemmer et al., 2011; Souza et al., 2012). Besides, IL-10 (which suppresses inflammation) producing $\mathrm{T}$ cells are augmented in artesunate treated mice (Thomé et al., 2016). Although there is rapid decrease in leukocyte accumulation in brain of artesunate treated ECM (Clemmer et al., 2011; Thomé et al., 2016), whether it is through the same mechanism of restricting leucocytes infiltration in to CNS as it for FTY720 is unknown. It is possible that FTY720 by down regulating $\mathrm{S}_{\mathrm{PR}}$ during late stage infection may lead to breach of $\mathrm{BBB}$ which may facilitate effective delivery of artesunate to central nervous system (CNS) for execution of immune-protective response against malaria. Some transient pharmacological inhibition studies of $\mathrm{S}_{\mathrm{P}} \mathrm{PR}_{1}$ in brain endothelial cell also highlight enhanced delivery and accumulation of therapeutics drugs in to the CNS (Cannon et al., 2012; Yanagida et al., 2017) supporting this hypothetical dysregulated $\mathrm{S}_{\mathrm{PR}}$ signaling axis as a possible target in modern therapeutics. Besides, S1P induction of NO release from endothelial cell (Igarashi et al., 2001) in mediating protective immune-response cannot be ruled out as the bioavailability of NO has been associated with resistance to malaria in previous clinical studies (Yeo et al., 2008; Dhangadamajhi et al., 2009). However, the effect of S1P and $\mathrm{S}_{1} \mathrm{PR}_{1}$ signaling in human malaria has not been investigated in terms of NO production and subsequent clinical outcome.

Previous studies investigating the effects of Plasmodium falciparum infections on blood indices show reduction of platelet count (thrombocytopenia) and RBCs (anemia), the two major sources for plasma S1P to be frequent and are responsible for clinical severity with fatal outcome (Birhanu et al., 2017;
Punsawad and Viriyavejakul, 2017; Dhangadamajhi et al., 2019). Further, platelet count has been delineated to resolve rapidly with recovery in the absence of any additional and specific treatment (Khan et al., 2012). Also, thrombocytopenia and anemia have been associated with a reduction in S1P level (Ono et al., 2013; Punsawad and Viriyavejakul, 2017). Although platelets release S1P into the blood circulation only after activation, whether such activation occurs during falciparum infection needs to be investigated. Based on significant correlation between platelet count and plasma S1P (Ono et al., 2013; Punsawad and Viriyavejakul, 2017), and their association with severity of malaria, it is reasonable to speculate the contribution of platelet to plasma S1P in malaria. On the other hand, S1P gradient and S1PR signaling (specifically through $S 1 \mathrm{PR}_{1}$ and partly by $\mathrm{S}_{\mathrm{PR}}$ under stress) were shown essential for platelet formation from megakaryocytes and their shedding in to the circulation (Zhang et al., 2012). Therefore, reduced plasma S1P with impaired S1PR signaling during falciparum infection might affect thrombopoiesis and could be the cause of observed thrombocytopenia. Since, platelets harbor endothelial cell protective factors (Nachman and Rafii, 2008), their loss upon reduced S1P in plasma may contribute indirectly to endothelial dysfunction. Whether, platelets function as plasma source of S1P during falciparum infection and/or thrombocytopenia in malaria is a consequence of reduced S1P in plasma is yet to be investigated. Although low level of S1P in plasma is associated with cerebral malaria and ARDS (Finney et al., 2011), its concentration in other forms of sub-clinical severe malaria needs further investigation. Besides, the role of S1P in endothelial dysfunction, inflammation, and NO production is largely unknown in human malaria. Therefore, it is imperative to investigate the prognostic implications of S1P in the context of severe falciparum malaria for its possible utility as adjunctive therapeutics in severe malaria. 


\section{RBC AND MALARIA IN THE CONTEXT OF S1P}

Owing to the major source of S1P in the blood and preferential site for parasite seclusion, the role of RBCs in the context of $\mathrm{S} 1 \mathrm{P}$ is critical. In a recent in vitro study by our group, it was shown that erythrocytic inhibition of SPHK1 leading to reduced intracellular S1P level arrested parasite growth and ultimately to cell death possibly due to impaired glycolysis (Sah et al., 2019). It was suggested that the deprivation of intra-erythrocytic $\mathrm{S} 1 \mathrm{P}$ hindered the binding of deoxy-Hb to plasma membrane thereby decreasing the translocation of the glycolytic enzyme, Glyceraldehyde 3-phosphate dehydrogenase (GAPDH) from the erythrocyte plasma membrane to the cytosol (Sun et al., 2016; Sah et al., 2019). This indicates that besides hemoglobin (major nutrient source for the intra-cellular malaria parasite), intraerythrocytic level of S1P is important for parasite growth as well, at least for the smooth operation of glycolysis in order to meet its high energy demand. Further, RBC being the main repository for S1P due to its capability to import sphingosine from the plasma (Ito et al., 2007), high SPHK1 activity (Hanel et al., 2007; Pappu et al., 2007), and lack or low activity of S1P degrading enzymes (Ito et al., 2007; Selim et al., 2011) may render survival advantage to the obligatory parasite. In addition, metabolic acidosis, the common cause of severe falciparum malaria could be the consequence of S1P mediated glycolysis boost in parasite infected RBC which can lead to increased lactate production. However, the fact that plasma level of S1P is crucial, and its low level has been attributed to cause severe malaria. Although, anemia and thrombocytopenia (which are common during severe malaria) terrify the condition of reduced plasma S1P, there is no study conducted till date addressing whether erythrocytic content of S1P is maintained despite decreased plasma S1P level during severe malaria. Previous study documents RBC content of S1P in non-malaria anemic patients to be similar compared to healthy individual (Selim et al., 2011). Intriguingly, Knapp et al. have documented perpetual reduced plasma S1P concentration as a stimulant for enhanced SPHK1 expression in erythrocytes in myocardial infarction (Knapp et al., 2013). During malaria infection, due to prolonged reduction in plasma S1P, parasite infected and/or non-infected RBCs might also be induced for increased rate of S1P production. Besides, trans-cellular S1P transportation from un-infected RBC to infected RBCs in rosette can't be ruled out. Rosette formation (aggregation of uninfected RBCs around a parasite infected RBC) is shown to be virulent in malaria and is region specific (Rowe et al., 2009; Rout et al., 2012). However, what triggers rosette formation is unknown. It is possible that poor intracellular S1P in parasite infected RBC may favor its binding with un-infected RBCs in rosette for auxiliary $\mathrm{S} 1 \mathrm{P}$ to the growing parasite through trans-cellular transportation. In a recent study, the observation of time dependent decrease in SPHK1 activity in infected RBC in vitro culture of falciparum parasite without affecting normal RBC (Sah et al., 2020) supports a possible acquisition of S1P from nearby uninfected cells. Investigation on this aspect would thus be helpful in better understanding on involvement of S1P in rosette formation and subsequent complicacy in severe malaria. Further, uptake of
S1P carrier proteins by the infected erythrocytes during in vitro culture (El Tahir et al., 2003) or their significant loss from plasma in malaria infected patients compared to the healthy individual (Visser et al., 2013) suggests strategic reduction of S1P export to the plasma by the parasite during malaria infection. Therefore, we speculate that intra-erythrocytic level of S1P adequate for parasite growth might be maintained during malaria and that decreased S1P efflux to plasma due to insufficient acceptors (Figure 2) may lead to S1P mediated various patho-physiological conditions of malaria.

\section{THERAPEUTIC OPPORTUNITIES}

Up to now it is clear that Sphk1/S1P signaling nexus and maintenance of adequate S1P level in erythrocytes is essential for intra-cellular parasitic growth (Sah et al., 2019), whereas low plasma S1P concentration contributes to severe manifestation of malaria. Therefore, reduction of RBC content of S1P and/or augmentation of plasma S1P through efflux from cellular sources could be an adjunctive therapeutic opportunities against severe malaria. Since S1P level in body fluids and cellular compartments is tightly regulated by complex interplay of S1P metabolizing enzymes, transporters, chaperones, and signaling receptors, one or more of these could be induced, inhibited or modulated as per requirement for S1P-targeted therapeutic approaches. Amongst the various S1P receptors targeting agents, functional antagonist to $\mathrm{S}_{\mathrm{PR}}$ such as Fingolimod (also known as FTY720$\mathrm{P} /$ Gilenya) and Siponimod (antagonist to $\mathrm{S} 1 \mathrm{PR}_{1}$ and $\mathrm{S} 1 \mathrm{PR}_{5}$ ) are FDA-approved drugs (Cartier and Hla, 2019). These drugs are shown to be effective against multiple sclerosis (MS), relapse remitting MS, neuro degenerative diseases, and cancer in several clinical trials (Cartier and Hla, 2019). Further, because of the acute agonistic action upon initial binding Fingolimod has also been reported to induce $S 1 \mathrm{PR}_{1}$ in megakaryocytes resulting in rapid platelet release (Zhang et al., 2012). Keeping in view of the constructive role of FTY720 in maintaining vascular integrity, survival benefits against CM and importance of platelets biology in malaria pathogenesis, FTY720 and related drugs should also be evaluated for their effectiveness in human clinical trial of malaria.

Regulation or inhibition of metabolic enzymes, particularly SPHK1 in RBC and deprivation of RBC content of S1P could be a potent therapeutic against malaria infection. A recent article by Pulkoski-Gross and Obeid (2018) describes SPHK1 regulation at different levels starting from transcription to post-translational modification through the use of long non-coding RNAs, micro RNAs, small interfering RNAs, and physiological and pharmacological stimuli. However, RBC being devoid of nucleus and genetic material, these methods of regulation seem ineffective. On the other hand, requirement of membrane localization for the cytosol resident SPHK1 for its ultimate functioning leave a hope to examine inhibitors of SPHK1 interaction with membranes as possible drug compound. Inhibition of SPHK1 phosphorylation at serine 225 has enabled reduced translocation to membrane resulting into deregulated S1P in Leishmaniasis infected macrophages (Arish et al., 2018). Reduced SPHK1 activity in falciparum infected RBCs has also 

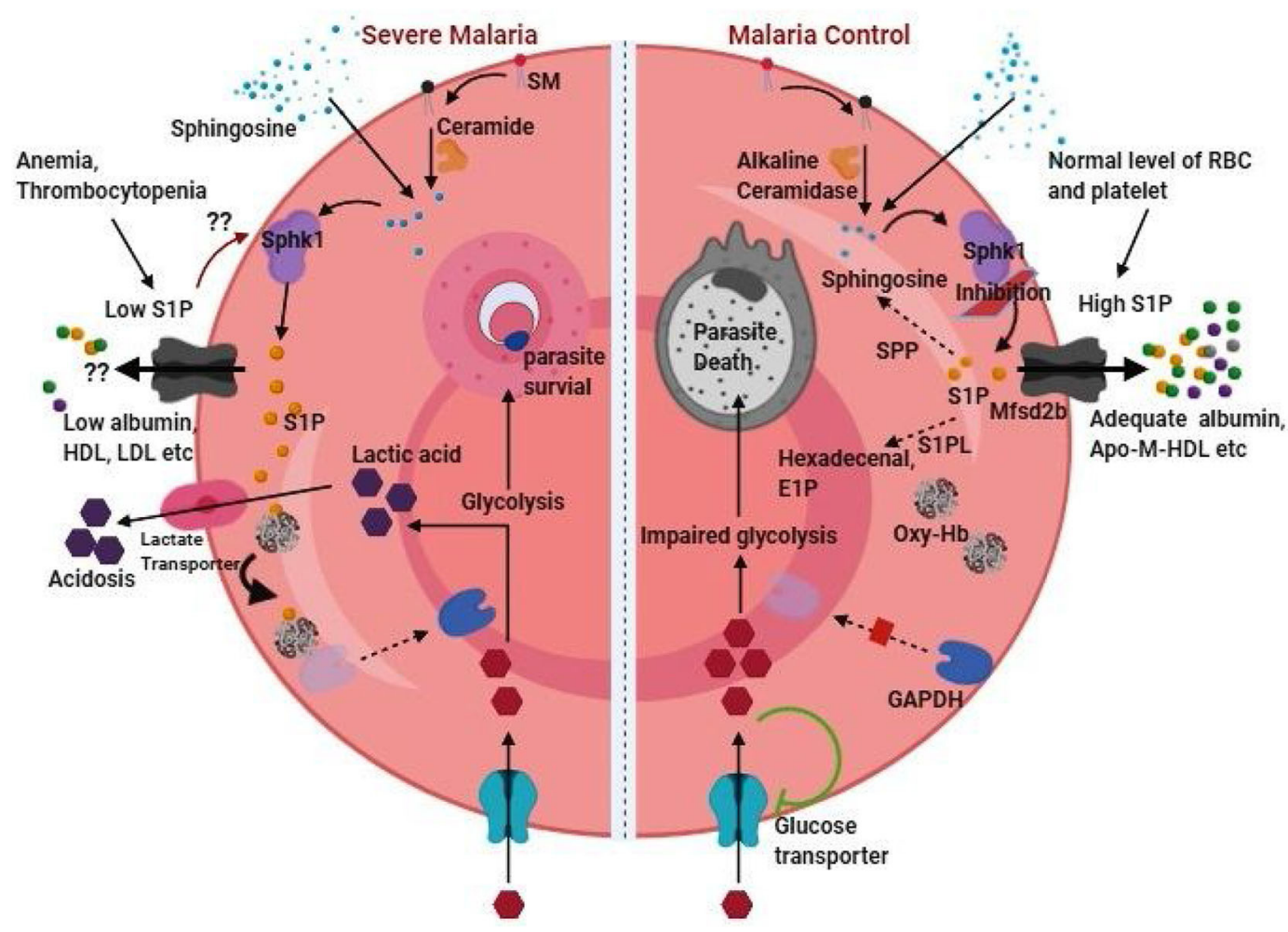

FIGURE 2 | RBC content of S1P as therapeutic target in malaria. RBC content of S1P can function as double-edged sword in malaria pathogenesis by provoking severe malaria (left half of the figure) or can be targeted for malaria control (right half of the figure). Thrombocytopenia and anemia, which are common in malaria indicates loss of two important sources of plasma S1P. Besides, depletion of acceptor molecules such as ApoM and albumin during malaria infection is expected to further harsh the condition of low plasma S1P level by reducing S1P efflux from these cellular sources. On the other hand, low level of plasma S1P might induces SPHK1 for phosphorylation of sphingosine synthesizing S1P in RBC. Sphingosine in RBC can be available as an intermediate of sphingolipid metabolism or directly be incorporated from the plasma. While intra-cellular S1P in RBC facilitate enhanced glycolysis essential for parasite growth, release of lactic acid byproduct leads to the severe condition of acidosis in malaria. Thus, malaria control (right half of the figure) can be achieved through S1P deprivation in parasite infected erythrocyte either by sphk1 inhibition, intracellular degradation by stimulation of S1P phosphatase and lyase, and/or promoting S1P exports in presence of adequate level of acceptor molecules. High plasma S1P has the beneficial role of protection against malaria. The (??) represents our hypothesis based on experimental evidences in different conditions or diseases.

been documented due to the lack of phosphorylation (Sah et al., 2020). Recently, GPCR proteins such as bradykinin receptors and muscarinic M3 receptor were shown to induce SPHK1 translocation to membrane (ter Braak et al., 2009; Bruno et al., 2018) and thus their inhibition would be provocative of future research. Further, cellular degradation of SPHK1 leading to loss of S1P in RBCs may also be an alternative approach of restricting intracellular parasite growth. Although on-target inhibition or degradation of SPHK1 is likely to preclude the possibility of trans-cellular S1P transport from uninfected RBCs to parasite infected RBC in rosette, undesirable degradation in other cell types may limit the use of these drugs. Further, this could also prevent participation of RBC as a source to plasma S1P as well hampering the protective effect of S1P against malaria. It is noteworthy that platelets production of S1P is largely mediated by SPHK2 (Urtz et al., 2015). Thus, platelet induction of S1P release could replenish plasma S1P and may play a crucial role in such case. Future studies in this aspect would render additional insights as to the role of RBC and platelets derived S1P in malaria. Of the several compounds, 2-(p-hydroxyanilino)-4-(pchlorophenyl) thiazole (also known as SK1 II) has been shown to induce SPHK1 degradation through lysosomal pathway (Ren et al., 2010). Chloroquine (CQ), on the other hand, has been shown to reverse SK1 II mediated degradation of SPHK1 (Ren et al., 2010). CQ though does not affect de novo synthesis of S1P derivatives; it restores S1P level in the cell through disrupting autophagy or lyso-somal degradation of enzymes by increasing the lysomal $\mathrm{pH}$. Therefore, investigation on whether SK1 II also has its effect in $\mathrm{RBC} /$ parasite infected $\mathrm{RBC}$ which lack lysosome, or whether CQ modulates SPHK1 function in these cells upon SK1 II treatment would be important for possible targeted degradation of SPHK1.

Stimulation of S1P degradation in parasite infected RBC would be another appreciable approach. Although, RBC was reported as incapable of degrading S1P due to lack of S1PL and SPP enzymes (Ito et al., 2007), low level of these enzymes have been detected (Selim et al., 2011). Further, marked reduction of S1P in prolong storage of RBC (Selim et al., 2011; Dong 
et al., 2012) support the plausible S1P degradation in RBC. It is unknown whether expression of these S1P degrading enzymes are induced or affected by the malaria parasite. However, SPP induction in iRBCs would be helpful in two ways. First, S1P level in RBCs would be reduced as required for therapeutics because of its degradation into Sphingosine and phosphate. Second, increased intra-cellular content of sphingosine might play an additional role of inducing eryptosis due to phosphatidyl serine exposure at RBC surface (erythrocyte death characterized by cell shrinkage) as reported previously (Qadri et al., 2011). However, it is unknown whether sphingosine could induce eryptosis in iRBCs as well. Since RBC serves as important source for the plasma level of S1P, cellular depletion of S1P via facilitated import into plasma through chaperone proteins (especially through ApoMHDL) would be of therapeutic interest. This perspective of intracellular S1P depletion would be valuable by affecting parasite growth in infected RBCs as well as increasing plasma level of S1P as required for protection. Although albumin too function as S1P acceptor, the observation of increased albumin in cerebrospinal fluid impairing BBB function of Malawian children with CM (Brown et al., 2001) and reported S1PR 1 internalization upon albumin-S1P binding precludes its utility in therapeutics use in malaria. Of note, administration of engineered ApoM with long plasma half-life has resulted into increased plasma concentration of S1P and cardiac protection with recovery from stroke in experimental mice (Swendeman et al., 2017). Similar study is warranted in experimental model of malaria and whether there is deprivation of the RBC content of S1P through increased efflux upon adequate bio-availability of engineered ApoM needs to be investigated. Because, parasite dependency on RBC content of S1P for survival in infected cell may complicate its export to plasma. Alternatively, induction of S1P transporters in RBC and platelets would be additional opportunity for S1P-targeted drug development in malaria.

\section{CONCLUSION AND FUTURE PERSPECTIVES}

In summary, S1P seems to play a double-edged sword in malaria pathogenesis. While intracellular content of S1P in infected RBCs is essential for parasite growth and development, its low level in plasma is associated with cerebral malaria in mouse model and human studies. However, how reduced S1P concentration in plasma affects other forms of sub-clinical severe malaria is yet to be materialized. Although diminished S1P concentration

\section{REFERENCES}

Alvarez, S. E., Harikumar, K. B., Hait, N. C., Allegood, J., Strub, G. M., Kim, E. Y., et al. (2010). Sphingosine-1-phosphate is a missing cofactor for the E3 ubiquitin ligase TRAF2. Nature 465, 1084-1088. doi: 10.1038/nature09128

Anada, Y., Igarashi, Y., and Kihara, A. (2007). The immunomodulator FTY720 is phosphorylated and released from platelets. Eur. J. Pharmacol. 568, 106-111. doi: 10.1016/j.ejphar.2007.04.053

Ancellin, N., Colmont, C., Su, J., Li, Q., Mittereder, N., Chae, S.-S., et al. (2002). Extracellular export of sphingosine kinase-1 enzyme Sphingosine 1-phosphate in plasma is likely to induce S1P synthesis in RBC, it is yet to be confirmed in parasite infected and/or non-infected RBCs through experimental studies in malaria. Further, whether S1P is involved in inducing rosette formation during falciparum infection would be important to understand rosette mediated complicacy in severe malaria. The fact that bioavailability of S1P is a tightly regulated process and its function is modulated by acceptor chaperones in the plasma. Thus, screening of functional variants in genes regulating S1P level in the plasma and S1P receptors, proportion of plasma S1P bound to albumin or ApoM HDL and their association with clinical manifestation of malaria would be helpful. Although kidney function to prevent urinal secretion of S1P, in malaria related renal failure (the most common severe complication after cerebral malaria), urinal detection of S1P could serve as a prognostic indicator and needs investigation in this line. Hitherto, substantial evidences suggest plasma S1P is crucial for differential manifestation of malaria. Therefore, selective inhibition of S1P synthesis in RBC, its degradation or abatement though supplementation of adequate acceptor molecules leading to augmented plasma level S1P may impair RBC growth of parasite and protect from severe malaria. Although the involvement of S1P in malaria pathogenesis has been studied only recently; more studies are warranted to answer several of these un-resolved questions before its implication as therapeutics.

\section{AUTHOR CONTRIBUTIONS}

GD: conceived the original idea, prepared all figures, and the first draft of manuscript. SS: interpreted the manuscript drafting for important intellectual content. All authors discussed and contributed to the final manuscript.

\section{FUNDING}

The present review is an upshot of the project proposal submitted to ICMR, Govt. of India for funding by both the authors. The funding agency has no role in designing, drafting, and decision to submit the review article for publication.

\section{ACKNOWLEDGMENTS}

We thankfully acknowledge the authors whose contribution have been cited and would like to apologize to those whose published articles could not be cited due to space constraints. 
Birhanu, M., Asres, Y., Adissu, W., Yemane, T., Zemene, E., and Gedefaw, L. (2017). Hematological parameters and hemozoin-containing leukocytes and their association with disease severity among malaria infected children: a crosssectional study at Pawe General Hospital, Northwest Ethiopia. Interdiscip. Perspect. Infect. Dis. 2017:8965729. doi: 10.1155/2017/8965729

Blaho, V. A., Galvani, S., Engelbrecht, E., Liu, C., Swendeman, S. L., Kono, M., et al. (2015). HDL-bound sphingosine-1-phosphate restrains lymphopoiesis and neuroinflammation. Nature 523, 342-346. doi: 10.1038/nature 14462

Blaho, V. A., and Hla, T. (2014). An update on the biology of sphingosine 1-phosphate receptors. J. Lipid Res. 55, 1596-1608. doi: 10.1194/jlr.R046300

Bode, C., Sensken, S.-C., Peest, U., Beutel, G., Thol, F., Levkau, B., et al. (2010). Erythrocytes serve as a reservoir for cellular and extracellular sphingosine 1-phosphate. J. Cell. Biochem. 109, 1232-1243. doi: 10.1002/jcb.22507

Brown, H., Rogerson, S., Taylor, T., Tembo, M., Mwenechanya, J., Molyneux, M., et al. (2001). Blood-brain barrier function in cerebral malaria in Malawian children. Am. J. Trop. Med. Hyg. 64, 207-213. doi: 10.4269/ajtmh.2001.64.207

Bruno, G., Cencetti, F., Bernacchioni, C., Donati, C., Blankenbach, K. V., Thomas, D., et al. (2018). Bradykinin mediates myogenic differentiation in murine myoblasts through the involvement of SK1/Spns2/S1P2 axis. Cell. Signal. 45, 110-121. doi: 10.1016/j.cellsig.2018.02.001

Cannon, R. E., Peart, J. C., Hawkins, B. T., Campos, C. R., and Miller, D. S. (2012). Targeting blood-brain barrier sphingolipid signaling reduces basal Pglycoprotein activity and improves drug delivery to the brain. Proc. Natl. Acad. Sci. U.S.A. 109, 15930-15935. doi: 10.1073/pnas.1203534109

Cantalupo, A., and Di Lorenzo, A. (2016). S1P signaling and de novo biosynthesis in blood pressure homeostasis. J. Pharmacol. Exp. Ther. 358, 359-370. doi: 10.1124/jpet.116.233205

Cartier, A., and Hla, T. (2019). Sphingosine 1-phosphate: lipid signaling in pathology and therapy. Science 366:eaar5551. doi: 10.1126/science.aar5551

Chan, H., and Pitson, S. M. (2013). Post-translational regulation of sphingosine kinases. Biochim. Biophys. Acta 1831, 147-156. doi: 10.1016/j.bbalip.2012.07.005

Christoffersen, C., Obinata, H., Kumaraswamy, S. B., Galvani, S., Ahnström, J., Sevvana, M., et al. (2011). Endothelium-protective sphingosine-1-phosphate provided by HDL-associated apolipoprotein M. Proc. Natl. Acad. Sci. U.S.A. 108, 9613-9618. doi: 10.1073/pnas.1103187108

Clemmer, L., Martins, Y., Zanini, G., Frangos, J., and Carvalho, L. (2011). Artemether and artesunate show the highest efficacies in rescuing mice with late-stage cerebral malaria and rapidly decrease leukocyte accumulation in the brain. Antimicrob. Agents Chemother. 55, 1383-1390. doi: 10.1128/AAC.01277-10

Dhangadamajhi, G., Mohapatra, B. N., Kar, S. K., and Ranjit, M. (2009). Endothelial nitric oxide synthase gene polymorphisms and Plasmodium falciparum infection in Indian adults. Infect. Immun. 77, 2943-2947. doi: 10.1128/IAI.00083-09

Dhangadamajhi, G., Panigrahi, S., Roy, S., and Tripathy, S. (2019). Effect of Plasmodium falciparum infection on blood parameters and their association with clinical severity in adults of Odisha, India. Acta Trop. 190, 1-8. doi: 10.1016/j.actatropica.2018.10.007

Dondorp, A. M., Yeung, S., White, L., Nguon, C., Day, N. P., Socheat, D., et al. (2010). Artemisinin resistance: current status and scenarios for containment. Nat. Rev. Microbiol. 8, 272-280. doi: 10.1038/nrmicro2331

Dong, A., Sunkara, M., Panchatcharam, M., Salous, A., Selim, S., Morris, A. J., et al. (2012). Synergistic effect of anemia and red blood cells transfusion on inflammation and lung injury. Adv. Hematol. 2012:924042. doi: $10.1155 / 2012 / 924042$

Donoviel, M. S., Hait, N. C., Ramachandran, S., Maceyka, M., Takabe, K., Milstien, S., et al. (2015). Spinster 2, a sphingosine-1-phosphate transporter, plays a critical role in inflammatory and autoimmune diseases. FASEB J. 29, 5018-5028. doi: 10.1096/fj.15-274936

Ebenezer, D. L., Berdyshev, E., Bronova, I. A., Tiruppathi, C., Kumarova, Y., Benevolenskaya, E. V., et al. (2019). Pseudomonas aeruginosa stimulates nuclearsphingosine-1-phosphate generation and epigenetic regulation of lung inflammatory injury. Thorax 74, 579-591. doi: 10.1136/thoraxjnl-2018-212378

El Tahir, A., Malhotra, P., and Chauhan, V. S. (2003). Uptake of proteins and degradation of human serum albumin by Plasmodium falciparum-infected human erythrocytes. Malar. J. 2:11. doi: 10.1186/1475-2875-2-11
Faber, K., Hvidberg, V., Moestrup, S. K., Dahlbäck, B., and Nielsen, L. B. (2006) Megalin is a receptor for apolipoprotein $\mathrm{M}$, and kidney-specific megalindeficiency confers urinary excretion of apolipoprotein M. Mol. Endocrinol. 20, 212-218. doi: 10.1210/me.2005-0209

Finney, C. A., Hawkes, C. A., Kain, D. C., Dhabangi, A., Musoke, C., Cserti-Gazdewich, C., et al. (2011). S1P is associated with protection in human and experimental cerebral malaria. Mol. Med. 17, 717-725. doi: 10.2119/molmed.2010.00214

Forrest, M., Sun, S.-Y., Hajdu, R., Bergstrom, J., Card, D., Doherty, G., et al. (2004). Immune cell regulation and cardiovascular effects of sphingosine 1phosphate receptor agonists in rodents are mediated via distinct receptor subtypes. J. Pharmacol. Exp. Ther. 309, 758-768. doi: 10.1124/jpet.103.062828

Fukuhara, S., Simmons, S., Kawamura, S., Inoue, A., Orba, Y., Tokudome, T., et al. (2012). The sphingosine-1-phosphate transporter Spns2 expressed on endothelial cells regulates lymphocyte trafficking in mice. J. Clin. Invest. 122, 1416-1426. doi: 10.1172/JCI60746

Galvani, S., Sanson, M., Blaho, V. A., Swendeman, S. L., Obinata, H., Conger, H., et al. (2015). HDL-bound sphingosine 1-phosphate acts as a biased agonist for the endothelial cell receptor S1P1 to limit vascular inflammation. Sci. Signal. 8, 79-79. doi: 10.1126/scisignal.aaa2581

Guo, S., Yu, Y., Zhang, N., Cui, Y., Zhai, L., Li, H., et al. (2014). Higher level of plasma bioactive molecule sphingosine 1-phosphate in women is associated with estrogen. Biochim. Biophys. Acta 1841, 836-846. doi: 10.1016/j.bbalip.2014.02.005

Hait, N. C., Allegood, J., Maceyka, M., Strub, G. M., Harikumar, K. B., Singh, S. K., et al. (2009). Regulation of histone acetylation in the nucleus by sphingosine-1phosphate. Science 325, 1254-1257. doi: 10.1126/science.1176709

Hammad, S. M., Pierce, J. S., Soodavar, F., Smith, K. J., Al Gadban, M. M., Rembiesa, B., et al. (2010). Blood sphingolipidomics in healthy humans: impact of sample collection methodology. J. Lipid Res. 51, 3074-3087. doi: 10.1194/jlr.D008532

Hanel, P., Andréani, P., and Graler, M. H. (2007). Erythrocytes store and release sphingosine 1-phosphate in blood. FASEB J. 21, 1202-1209. doi: 10.1096/fj.06-7433com

Hatoum, D., Haddadi, N., Lin, Y., Nassif, N. T., and Mc Gowan, E. M. (2017). Mammalian sphingosine kinase (SphK) isoenzymes and isoform expression: challenges for SphK as an oncotarget. Oncotarget 8, 36898-36929. doi: 10.18632/oncotarget.16370

Hempel, C., Sporring, J., and Kurtzhals, J. A. L. (2019). Experimental cerebral malaria is associated with profound loss of both glycan and protein components of the endothelial glycocalyx. FASEB J. 33, 2058-2071. doi: 10.1096/fj.201800657R

Hisano, Y., Kobayashi, N., Yamaguchi, A., and Nishi, T. (2012). Mouse SPNS2 functions as a sphingosine-1-phosphate transporter in vascular endothelial cells. PLoS ONE 7:e38941. doi: 10.1371/journal.pone.0038941

Hofrichter, M. A., Mojarad, M., Doll, J., Grimm, C., Eslahi, A., Hosseini, N. S., et al. (2018). The conserved p. Arg108 residue in S1PR2 (DFNB68) is fundamental for proper hearing: evidence from a consanguineous Iranian family. BMC Med. Genet. 19:81. doi: 10.1186/s12881-018-0598-5

Huang, L.-Z., Gao, J.-L., Pu, C., Zhang, P.-H., Wang, L.-Z., Feng, G., et al. (2015). Apolipoprotein M: research progress, regulation and metabolic functions. Mol. Med. Rep. 12, 1617-1624. doi: 10.3892/mmr.2015.3658

Idro, R., Kakooza-Mwesige, A., Balyejjussa, S., Mirembe, G., Mugasha, C., Tugumisirize, J., et al. (2010). Severe neurological sequelae and behaviour problems after cerebral malaria in Ugandan children. BMC Res. Notes 3:104. doi: 10.1186/1756-0500-3-104

Igarashi, J., Bernier, S. G., and Michel, T. (2001). Sphingosine 1-phosphate and activation of endothelial nitric-oxide synthase differential regulation of Akt and MAP kinase pathways by EDG and bradykinin receptors in vascular endothelial cells. J. Biol. Chem. 276, 12420-12426. doi: 10.1074/jbc.M008375200

Ingham, N. J., Carlisle, F., Pearson, S., Lewis, M. A., Buniello, A., Chen, J., et al. (2016). S1PR2 variants associated with auditory function in humans and endocochlear potential decline in mouse. Sci. Rep. 6:28964. doi: 10.1038/srep28964

Ito, K., Anada, Y., Tani, M., Ikeda, M., Sano, T., Kihara, A., et al. (2007). Lack of sphingosine 1-phosphate-degrading enzymes in erythrocytes. Biochem. Biophys. Res. Commun. 357, 212-217. doi: 10.1016/j.bbrc.2007.03.123 
Jonnalagadda, D., Sunkara, M., Morris, A. J., and Whiteheart, S. W. (2014). Granule-mediated release of sphingosine-1-phosphate by activated platelets. Biochim. Biophys. Acta 1841, 1581-1589. doi: 10.1016/j.bbalip.2014.08.013

Kai, M., Sakane, F., Jia, Y.-J., Imai, S., Yasuda, S., and Kanoh, H. (2006). Lipid phosphate phosphatases 1 and 3 are localized in distinct lipid rafts. J. Biochem. 140, 677-686. doi: 10.1093/jb/mvj195

Karuna, R., Park, R., Othman, A., Holleboom, A. G., Motazacker, M. M., Sutter, I., et al. (2011). Plasma levels of sphingosine-1-phosphate and apolipoprotein $M$ in patients with monogenic disorders of HDL metabolism. Atherosclerosis 219, 855-863. doi: 10.1016/j.atherosclerosis.2011.08.049

Kerage, D., Brindley, D., and Hemmings, D. (2014). Novel insights into the regulation of vascular tone by sphingosine 1-phosphate. Placenta 35, 86-92. doi: 10.1016/j.placenta.2013.12.006

Keul, P., Polzin, A., Kaiser, K., Gräler, M., Dannenberg, L., Daum, G., et al. (2019). Potent anti-inflammatory properties of HDL in vascular smooth muscle cells mediated by HDL-S1P and their impairment in coronary artery disease due to lower HDL-S1P: a new aspect of HDL dysfunction and its therapy. FASEB J. 33, 1482-1495. doi: 10.1096/fj.201801245R

Khan, S. J., Abbass, Y., and Marwat, M. A. (2012). Thrombocytopenia as an indicator of malaria in adult population. Malar. Res. Treat. 2012:405981. doi: 10.1155/2012/405981

Kharel, Y., Mathews, T. P., Gellett, A. M., Tomsig, J. L., Kennedy, P. C., Moyer, M. L., et al. (2011). Sphingosine kinase type 1 inhibition reveals rapid turnover of circulating sphingosine 1-phosphate. Biochem. J. 440, 345-353. doi: 10.1042/BJ20110817

Kharel, Y., Raje, M., Gao, M., Gellett, A. M., Tomsig, J. L., Lynch, K. R., et al. (2012). Sphingosine kinase type 2 inhibition elevates circulating sphingosine 1-phosphate. Biochem. J. 447, 149-157. doi: 10.1042/BJ20120609

Kimura, T., Sato, K., Kuwabara, A., Tomura, H., Ishiwara, M., Kobayashi, I., et al. (2001). Sphingosine 1-phosphate may be a major component of plasma lipoproteins responsible for the cytoprotective actions in human umbilical vein endothelial cells. J. Biol. Chem. 276, 31780-31785. doi: 10.1074/jbc.M104353200

Knapp, M., Lisowska, A., Zabielski, P., Musial, W., and Baranowski, M. (2013). Sustained decrease in plasma sphingosine-1-phosphate concentration and its accumulation in blood cells in acute myocardial infarction. Prostaglandins Other Lipid Mediat. 106, 53-61. doi: 10.1016/j.prostaglandins.2013.10.001

Kobayashi, N., Kawasaki-Nishi, S., Otsuka, M., Hisano, Y., Yamaguchi, A., and Nishi, T. (2018). MFSD2B is a sphingosine 1-phosphate transporter in erythroid cells. Sci. Rep. 8, 1-11. doi: 10.1038/s41598-018-23300-x

Kono, M., Mi, Y., Liu, Y., Sasaki, T., Allende, M. L., Wu, Y.-P., et al. (2004). The sphingosine-1-phosphate receptors S1P1, S1P2, and S1P3 function coordinately during embryonic angiogenesis. J. Biol. Chem. 279, 29367-29373. doi: 10.1074/jbc.M403937200

Ksiazek, M., Chacinska, M., Chabowski, A., and Baranowski, M. (2015). Sources, metabolism, and regulation of circulating sphingosine-1-phosphate. J. Lipid Res. 56, 1271-1281. doi: 10.1194/jlr.R059543

Kurano, M., Tsukamoto, K., Ohkawa, R., Hara, M., Iino, J., Kageyama, Y., et al. (2013). Liver involvement in sphingosine 1-phosphate dynamism revealed by adenoviral hepatic overexpression of apolipoprotein M. Atherosclerosis 229, 102-109. doi: 10.1016/j.atherosclerosis.2013.04.024

Liles, W. C., and Kain, K. C. (2014). Endothelial activation and dysfunction in the pathogenesis of microvascular obstruction in severe malaria-a viable target for therapeutic adjunctive intervention. J. Infect. Dis. 210, 163-164. doi: 10.1093/infdis/jiu035

Liu, M., Seo, J., Allegood, J., Bi, X., Zhu, X., Boudyguina, E., et al. (2014). Hepatic apolipoprotein $\mathrm{M}$ (apoM) overexpression stimulates formation of larger apoM/sphingosine 1-phosphate-enriched plasma high density lipoprotein. J. Biol. Chem. 289, 2801-2814. doi: 10.1074/jbc.M113.499913

Liu, X., Zhang, Q.-H., and Yi, G.-H. (2012). Regulation of metabolism and transport of sphingosine-1-phosphate in mammalian cells. Mol. Cell. Biochem. 363, 21-33. doi: 10.1007/s11010-011-1154-1

Liu, Y., Wada, R., Yamashita, T., Mi, Y., Deng, C.-X., Hobson, J. P., et al. (2000). Edg-1, the $G$ protein-coupled receptor for sphingosine-1phosphate, is essential for vascular maturation. J. Clin. Invest. 106, 951-961. doi: 10.1172/JCI10905
Loh, K. C., Baldwin, D., and Saba, J. D. (2011), Sphingolipid signaling and hematopoietic malignancies: to the rheostat and beyond. Anticancer Agents Med. Chem. 11, 782-793. doi: 10.2174/187152011797655159

Maceyka, M., Sankala, H., Hait, N. C., Le Stunff, H., Liu, H., Toman, R., et al. (2005). SphK1 and SphK2, sphingosine kinase isoenzymes with opposing functions in sphingolipid metabolism. J. Biol. Chem. 280, 37118-37129. doi: $10.1074 /$ jbc.M502207200

Maceyka, M., and Spiegel, S. (2014). Sphingolipid metabolites in inflammatory disease. Nature 510, 58-67. doi: 10.1038/nature13475

MacLennan, A. J., Benner, S. J., Andringa, A., Chaves, A. H., Rosing, J. L., Vesey, R., et al. (2006). The S1P2 sphingosine 1-phosphate receptor is essential for auditory and vestibular function. Hear. Res. 220, 38-48. doi: 10.1016/j.heares.2006.06.016

Mendoza, A., Bréart, B., Ramos-Perez, W. D., Pitt, L. A., Gobert, M., Sunkara, M., et al. (2012). The transporter Spns2 is required for secretion of lymph but not plasma sphingosine-1-phosphate. Cell Rep. 2, 1104-1110. doi: 10.1016/j.celrep.2012.09.021

Nacer, A., Movila, A., Baer, K., Mikolajczak, S. A., Kappe, S. H., and Frevert, U. (2012). Neuroimmunological blood brain barrier opening in experimental cerebral malaria. PLoS Pathog. 8:e1002982. doi: 10.1371/journal.ppat.1002982

Nacer, A., Movila, A., Sohet, F., Girgis, N. M., Gundra, U. M., Loke, P., et al. (2014). Experimental cerebral malaria pathogenesis-hemodynamics at the blood brain barrier. PLoS Pathog. 10:e1004528. doi: 10.1371/journal.ppat.1004528

Nachman, R. L., and Rafii, S. (2008). Platelets, petechiae, and preservation of the vascular wall. N. Engl. J. Med. 359, 1261-1270. doi: 10.1056/NEJMra0800887

Newton, P. N., Stepniewska, K., Dondorp, A., Silamut, K., Chierakul, W., Krishna, S., et al. (2013). Prognostic indicators in adults hospitalized with falciparum malaria in Western Thailand. Malar. J. 12:229. doi: 10.1186/1475-2875-12-229

Nojiri, T., Kurano, M., Tokuhara, Y., Ohkubo, S., Hara, M., Ikeda, H., et al. (2014). Modulation of sphingosine-1-phosphate and apolipoprotein $\mathrm{M}$ levels in the plasma, liver and kidneys in streptozotocin-induced diabetic mice. J. Diabetes Investig. 5, 639-648. doi: 10.1111/jdi.12232

Obinata, H., and Hla, T. (2019). Sphingosine 1-phosphate and inflammation. Int. Immunol. 31, 617-625. doi: 10.1093/intimm/dxz037

Oggungwan, K., Glaharn, S., Ampawong, S., Krudsood, S., and Viriyavejakul, P. (2018). FTY720 restores endothelial cell permeability induced by malaria sera. Sci. Rep. 8, 1-6. doi: 10.1038/s41598-018-28536-1

Ohkawa, R., Nakamura, K., Okubo, S., Hosogaya, S., Ozaki, Y., Tozuka, M., et al. (2008). Plasma sphingosine-1-phosphate measurement in healthy subjects: close correlation with red blood cell parameters. Ann. Clin. Biochem. 45, 356-363. doi: 10.1258/acb.2007.007189

Oluwayemi, I. O., Brown, B. J., Oyedeji, O. A., and Oluwayemi, M. A. (2013). Neurological sequelae in survivors of cerebral malaria. Pan Afr. Med. J. 15:88. doi: 10.11604/pamj.2013.15.88.1897

Ono, Y., Kurano, M., Ohkawa, R., Yokota, H., Igarashi, K., Aoki, J., et al. (2013). Sphingosine 1-phosphate release from platelets during clot formation: close correlation between platelet count and serum sphingosine 1-phosphate concentration. Lipids Health Dis. 12:20. doi: 10.1186/1476-511X-12-20

Oo, M. L., Chang, S.-H., Thangada, S., Wu, M.-T., Rezaul, K., Blaho, V., et al. (2011). Engagement of S1P 1-degradative mechanisms leads to vascular leak in mice. J. Clin. Invest. 121, 2290-2300. doi: 10.1172/JCI45403

Pappu, R., Schwab, S. R., Cornelissen, I., Pereira, J. P., Regard, J. B., Xu, Y., et al. (2007). Promotion of lymphocyte egress into blood and lymph by distinct sources of sphingosine-1-phosphate. Science 316, 295-298. doi: 10.1126/science.1139221

Peest, U., Sensken, S.-C., Andréani, P., Hänel, P., Van Veldhoven, P. P., and Gräler, M. H. (2008). S1P-lyase independent clearance of extracellular sphingosine 1phosphate after dephosphorylation and cellular uptake. J. Cell. Biochem. 104, 756-772. doi: $10.1002 /$ jcb. 21665

Pitson, S. M., Xia, P., Leclercq, T. M., Moretti, P. A., Zebol, J. R., Lynn, H. E., et al. (2005). Phosphorylation-dependent translocation of sphingosine kinase to the plasma membrane drives its oncogenic signalling. J. Exp. Med. 201, 49-54. doi: $10.1084 /$ jem.20040559

Pulkoski-Gross, M. J., and Obeid, L. M. (2018). Molecular mechanisms of regulation of sphingosine kinase 1. Biochim. Biophys. Acta 1863, 1413-1422. doi: 10.1016/j.bbalip.2018.08.015 
Punsawad, C., and Viriyavejakul, P. (2017). Reduction in serum sphingosine 1-phosphate concentration in malaria. PLoS ONE 12:e180631. doi: 10.1371/journal.pone.0180631

Punsawad, C., and Viriyavejakul, P. (2019). Expression of sphingosine kinase 1 and sphingosine 1-phosphate receptor 3 in malaria-associated acute lung injury/acute respiratory distress syndrome in a mouse model. PLOS ONE 14:e0222098. doi: 10.1371/journal.pone.0222098

Qadri, S. M., Bauer, J., Zelenak, C., Mahmud, H., Kucherenko, Y., Lee, S. H., et al. (2011). Sphingosine but not sphingosine-1-phosphate stimulates suicidal erythrocyte death. Cell. Physiol. Biochem. 28, 339-346. doi: 10.1159/000331750

Ren, S., Xin, C., Pfeilschifter, J., and Huwiler, A. (2010). A novel mode of action of the putative sphingosine kinase inhibitor 2-(p-hydroxyanilino)-4-(pchlorophenyl) thiazole (SKI II): induction of lysosomal sphingosine kinase 1 degradation. Cell. Physiol. Biochem. 26, 97-104. doi: 10.1159/000315110

Rout, R., Dhangadamajhi, G., Ghadei, M., Mohapatra, B. N., Kar, S. K., and Ranjit, M. (2012). Blood group phenotypes A and B are risk factors for cerebral malaria in Odisha, India. Trans. R. Soc. Trop. Med. Hyg. 106, 538-543. doi: 10.1016/j.trstmh.2012.05.014

Rowe, J. A., Claessens, A., Corrigan, R. A., and Arman, M. (2009). Adhesion of Plasmodium falciparum-infected erythrocytes to human cells: molecular mechanisms and therapeutic implications. Expert Rev. Mol. Med. 11:e16. doi: $10.1017 /$ S1462399409001082

Sah, R. K., Pati, S., Saini, M., Boopathi, P. A., Kochar, S. K., Kochar, D. K., et al. (2020). Reduction of sphingosine kinase 1 phosphorylation and activity in Plasmodium-infected erythrocytes. Front. Cell Dev. Biol. 8:80. doi: $10.3389 /$ fcell.2020.00080

Sah, R. K., Saini, M., Pati, S., and Singh, S. (2019). Plasmodium falciparum growth is regulated by Sphingosine 1 phosphate produced by Host Erythrocyte Membrane Sphingosine kinase 1. bioRxiv 756502. doi: 10.1101/756502

Salous, A. K., Panchatcharam, M., Sunkara, M., Mueller, P., Dong, A., Wang, Y., et al. (2013). Mechanism of rapid elimination of lysophosphatidic acid and related lipids from the circulation of mice. J. Lipid Res. 54, 2775-2784. doi: $10.1194 /$ jlr.M039685

Sanna, M. G., Wang, S.-K., Gonzalez-Cabrera, P. J., Don, A., Marsolais, D., Matheu, M. P., et al. (2006). Enhancement of capillary leakage and restoration of lymphocyte egress by a chiral S1P 1 antagonist in vivo. Nat. Chem. Biol. 2, 434-441. doi: 10.1038/nchembio804

Sattler, K., Gräler, M., Keul, P., Weske, S., Reimann, C.-M., Jindrová, H., et al. (2015). Defects of high-density lipoproteins in coronary artery disease caused by low sphingosine-1-phosphate content: correction by sphingosine-1-phosphate-loading. J. Am. Coll. Cardiol. 66, 1470-1485. doi: 10.1016/j.jacc.2015.07.057

Sattler, K. J., Elbasan, S., Keul, P., Elter-Schulz, M., Bode, C., Gräler, M. H., et al. (2010). Sphingosine 1-phosphate levels in plasma and HDL are altered in coronary artery disease. Basic Res. Cardiol. 105, 821-832. doi: 10.1007/s00395-010-0112-5

Schwab, S. R., Pereira, J. P., Matloubian, M., Xu, Y., Huang, Y., and Cyster, J. G. (2005). Lymphocyte sequestration through S1P lyase inhibition and disruption of S1P gradients. Science 309, 1735-1739. doi: 10.1126/science.1113640

Selim, S., Sunkara, M., Salous, A. K., Leung, S. W., Berdyshev, E. V., Bailey, A., et al. (2011). Plasma levels of sphingosine 1-phosphate are strongly correlated with haematocrit, but variably restored by red blood cell transfusions. Clin. Sci. 121, 565-572. doi: 10.1042/CS20110236

Sensken, S.-C., Bode, C., Nagarajan, M., Peest, U., Pabst, O., and Gräler, M. H. (2010). Redistribution of sphingosine 1-phosphate by sphingosine kinase 2 contributes to lymphopenia. J. Immunol. 184, 4133-4142. doi: 10.4049/jimmunol.0903358

Snider, A. J., Gandy, K. A. O., and Obeid, L. M. (2010). Sphingosine kinase: role in regulation of bioactive sphingolipid mediators in inflammation. Biochimie 92, 707-715. doi: 10.1016/j.biochi.2010.02.008

Souza, M. C., Paixao, F. H. M., Ferraris, F. K., Ribeiro, I., and Henriques, M., das G.M. (2012). Artesunate exerts a direct effect on endothelial cell activation and NF-B translocation in a mechanism independent of Plasmodium killing. Malar. Res. Treat. 2012:679090. doi: 10.1155/2012/679090

Strub, G. M., Maceyka, M., Hait, N. C., Milstien, S., and Spiegel, S. (2010). "Extracellular and intracellular actions of sphingosine-1-phosphate," in Sphingolipids as Signaling and Regulatory Molecules, eds C. Chalfant and M. Del Poeta (New York, NY: Springer), 141-155. doi: 10.1007/978-1-4419-6741-1_10
Sun, K., Zhang, Y., D’Alessandro, A., Nemkov, T., Song, A., Wu, H., et al. (2016). Sphingosine-1-phosphate promotes erythrocyte glycolysis and oxygen release for adaptation to high-altitude hypoxia. Nat. Commun. 7, 1-13. doi: $10.1038 /$ ncomms12086

Sun, X., Singleton, P. A., Letsiou, E., Zhao, J., Belvitch, P., Sammani, S., et al. (2012). Sphingosine-1-phosphate receptor -3 is a novel biomarker in acute lung injury. Am. J. Respir. Cell Mol. Biol. 47, 628-636. doi: 10.1165/rcmb.2012-0048OC

Sutter, I., Park, R., Othman, A., Rohrer, L., Hornemann, T., Stoffel, M., et al. (2014). Apolipoprotein M modulates erythrocyte efflux and tubular reabsorption of sphingosine-1-phosphate. J. Lipid Res. 55, 1730-1737. doi: 10.1194/jlr.M050021

Swendeman, S. L., Xiong, Y., Cantalupo, A., Yuan, H., Burg, N., Hisano, Y., et al. (2017). An engineered S1P chaperone attenuates hypertension and ischemic injury. Sci. Signal. 10:eaal2722. doi: 10.1126/scisignal.aal2722

Takabe, K., Paugh, S. W., Milstien, S., and Spiegel, S. (2008). “Inside-out” signaling of sphingosine-1-phosphate: therapeutic targets. Pharmacol. Rev. 60, 181-195. doi: $10.1124 /$ pr.107.07113

Tani, M., Ito, M., and Igarashi, Y. (2007). Ceramide/sphingosine/sphingosine 1-phosphate metabolism on the cell surface and in the extracellular space. Cell. Signal. 19, 229-237. doi: 10.1016/j.cellsig.2006.07.001

Tani, M., Sano, T., Ito, M., and Igarashi, Y. (2005). Mechanisms of sphingosine and sphingosine 1-phosphate generation in human platelets. J. Lipid Res. 46, 2458-2467. doi: 10.1194/jlr.M500268-JLR200

Taylor, W. R., Hanson, J., Turner, G. D., White, N. J., and Dondorp, A. M. (2012). Respiratory manifestations of malaria. Chest 142, 492-505. doi: 10.1378/chest.11-2655

ter Braak, M., Danneberg, K., Lichte, K., Liphardt, K., Ktistakis, N. T., Pitson, S. M., et al. (2009). G $\alpha$ q-mediated plasma membrane translocation of sphingosine kinase-1 and cross-activation of S1P receptors. Biochim. Biophys. Acta 1791, 357-370. doi: 10.1016/j.bbalip.2009.01.019

Thomé, R., de Carvalho, A. C., Alves da Costa, T., Ishikawa, L. L. W., FragaSilva, T. F. C., Sartori, A., et al. (2016). Artesunate ameliorates experimental autoimmune encephalomyelitis by inhibiting leukocyte migration to the central nervous system. CNS Neurosci. Ther. 22, 707-714. doi: 10.1111/cns. 12561

Thuy, A. V., Reimann, C.-M., Hemdan, N. Y., and Gräler, M. H. (2014). Sphingosine 1-phosphate in blood: function, metabolism, and fate. Cell. Physiol. Biochem. 34, 158-171. doi: 10.1159/000362992

Tibon, N. S., Ng, C. H., and Cheong, S. L. (2020). Current progress in antimalarial pharmacotherapy and multi-target drug discovery. Eur. J. Med. Chem. 188:111983. doi: 10.1016/j.ejmech.2019.111983

Tong, X., Lv, P., Mathew, A. V., Liu, D., Niu, C., Wang, Y., et al. (2014). The compensatory enrichment of sphingosine-1-phosphate harbored on glycated high-density lipoprotein restores endothelial protective function in type 2 diabetes mellitus. Cardiovasc. Diabetol. 13:82. doi: 10.1186/1475-2840-13-82

Urtz, N., Gaertner, F., von Bruehl, M.-L., Chandraratne, S., Rahimi, F., Zhang, L., et al. (2015). Sphingosine 1-phosphate produced by sphingosine kinase 2 intrinsically controls platelet aggregation in vitro and in vivo. Circ. Res. 117, 376-387. doi: 10.1161/CIRCRESAHA.115.306901

van der Heyde, H. C., Nolan, J., Combes, V., Gramaglia, I., and Grau, G. E. (2006). A unified hypothesis for the genesis of cerebral malaria: sequestration, inflammation and hemostasis leading to microcirculatory dysfunction. Trends Parasitol. 22, 503-508. doi: 10.1016/j.pt.2006.09.002

Venkataraman, K., Lee, Y.-M., Michaud, J., Thangada, S., Ai, Y., Bonkovsky, H. L., et al. (2008). Vascular endothelium as a contributor of plasma sphingosine 1-phosphate. Circ. Res. 102, 669-676. doi: 10.1161/CIRCRESAHA.107.165845

Venkataraman, K., Thangada, S., Michaud, J., Oo, M. L., Ai, Y., Lee, Y.-M., et al. (2006). Extracellular export of sphingosine kinase-1a contributes to the vascular S1P gradient. Biochem. J. 397, 461-471. doi: 10.1042/BJ20060251

Viriyavejakul, P., and Punsawad, C. (2020). Overexpression of sphingosine kinase-1 and sphingosine-1-phosphate receptor-3 in severe Plasmodium falciparum malaria with pulmonary edema. Biomed Res. Int. 2020:3932569. doi: $10.1155 / 2020 / 3932569$

Visser, B. J., Wieten, R. W., Nagel, I. M., and Grobusch, M. P. (2013). Serum lipids and lipoproteins in malaria-a systematic review and meta-analysis. Malar. J. 12:442. doi: 10.1186/1475-2875-12-442

Vu, T. M., Ishizu, A.-N., Foo, J. C., Toh, X. R., Zhang, F., Whee, D. M., et al. (2017). Mfsd2b is essential for the sphingosine-1-phosphate export in erythrocytes and platelets. Nature 550, 524-528. doi: 10.1038/nature24053 
Wilkerson, B. A., Grass, G. D., Wing, S. B., Argraves, W. S., and Argraves, K. M. (2012). Sphingosine 1-phosphate (S1P) carrier-dependent regulation of endothelial barrier high density lipoprotein (HDL)-S1P prolongs endothelial barrier enhancement as compared with albumin-S1P via effects on levels, trafficking, and signaling of S1P1. J. Biol. Chem. 287, 44645-44653. doi: $10.1074 /$ jbc.M112.423426

Xiong, Y., Yang, P., Proia, R. L., and Hla, T. (2014). Erythrocyte-derived sphingosine 1-phosphate is essential for vascular development. J. Clin. Invest. 124, 4823-4828. doi: 10.1172/JCI77685

Yanagida, K., Liu, C. H., Faraco, G., Galvani, S., Smith, H. K., Burg, N., et al. (2017). Size-selective opening of the blood-brain barrier by targeting endothelial sphingosine 1-phosphate receptor 1. Proc. Natl. Acad. Sci. U.S.A. 114, 4531-4536. doi: 10.1073/pnas.1618659114

Yatomi, Y., Yamamura, S., Hisano, N., Nakahara, K., Igarashi, Y., and Ozaki, Y. (2004). Sphingosine 1-phosphate breakdown in platelets. J. Biochem. 136, 495-502. doi: 10.1093/jb/mvh143

Yeo, T. W., Rooslamiati, I., Gitawati, R., Tjitra, E., Lampah, D. A., Kenangalem, E., et al. (2008). Pharmacokinetics of L-arginine in adults with moderately severe malaria. Antimicrob. Agents Chemother. 52, 4381-4387. doi: 10.1128/AAC.00421-08

Yeo, T. W., Weinberg, J. B., Lampah, D. A., Kenangalem, E., Bush, P., Chen, Y., et al. (2019). Glycocalyx breakdown is associated with severe disease and fatal outcome in Plasmodium falciparum malaria. Clin. Infect. Dis. 69, 1712-1720. doi: $10.1093 / \mathrm{cid} / \mathrm{ciz} 038$

Yu, Y., Guo, S., Feng, Y., Feng, L., Cui, Y., Song, G., et al. (2014). Phospholipid transfer protein deficiency decreases the content of S1P in HDL via the loss of its transfer capability. Lipids 49, 183-190. doi: 10.1007/s11745-013-3850-y

Zhang, H., Pluhackova, K., Jiang, Z., and Böckmann, R. A. (2016). Binding characteristics of sphingosine-1-phosphate to ApoM hints to assisted release mechanism via the ApoM calyx-opening. Sci. Rep. 6:30655. doi: 10.1038/srep30655

Zhang, L., Orban, M., Lorenz, M., Barocke, V., Braun, D., Urtz, N., et al. (2012). A novel role of sphingosine 1-phosphate receptor S1prl in mouse thrombopoiesis. J. Exp. Med. 209, 2165-2181. doi: 10.1084/jem.20121090

Zhang, X.-Y., Dong, X., Zheng, L., Luo, G.-H., Liu, Y.-H., Ekström, U., et al. (2003). Specific tissue expression and cellular localization of human apolipoprotein $\mathrm{M}$ as determined by in situ hybridization. Acta Histochem. 105, 67-72. doi: 10.1078/0065-1281-00687

Zhao, Y., Kalari, S. K., Usatyuk, P. V., Gorshkova, I., He, D., Watkins, T., et al. (2007). Intracellular generation of sphingosine 1-phosphate in human lung endothelial cells: role of lipid phosphate phosphatase-1 and sphingosine kinase 1. J. Biol. Chem. 282, 14165-14177. doi: 10.1074/jbc.M701279200

Zuo, S., Ge, H., Li, Q., Zhang, X., Hu, R., Hu, S., et al. (2017). Artesunate protected blood-brain barrier via sphingosine 1 phosphate receptor 1/phosphatidylinositol 3 kinase pathway after subarachnoid hemorrhage in rats. Mol. Neurobiol. 54, 1213-1228. doi: 10.1007/s12035-016-9732-6

Conflict of Interest: The authors declare that the research was conducted in the absence of any commercial or financial relationships that could be construed as a potential conflict of interest.

Copyright (C) 2020 Dhangadamajhi and Singh. This is an open-access article distributed under the terms of the Creative Commons Attribution License (CC BY). The use, distribution or reproduction in other forums is permitted, provided the original author(s) and the copyright owner(s) are credited and that the original publication in this journal is cited, in accordance with accepted academic practice. No use, distribution or reproduction is permitted which does not comply with these terms. 